\title{
REGIONAL ANALYSIS OF EXCESS BEDS \\ IN GENERAL HOSPITALS
}

Neville Doherty, Ph.D.

and

E. Susan Smith, M.A.

\section{Abstract}

This study examines projected surgical and medical bed needs for 1974 in Connecticut's general hospitals. The federal method for determining needs, based on fixed occupancy rates, is compared with an alternative based on probabilities of overcrowding.

Bed needs were equal when the two methods were applied on an individual hospital basis. For groups of hospitals in health service areas, the alternative indicated potential reductions in planned beds. Under the Federal plan the 1969 base of 8,976 beds should be increased to 9,578. This is 765 more beds than estimated as adequate by the alternative approach. When allowances are made for excess beds already constructed, the federal plan indicates a need for 469 more beds than does the alternative. Daily additions to per patient charges attributable to federally planned excess beds is estimated to lie between $\$ 4$ and $\$ 10$. These findings are significant for people concerned with methods for reducing hospital costs.

\section{INTRODUCTION}

Hospital planners in the United States are faced with a problem of meeting increasing demand for hospital services at optimal savings. For quality health care, more equipment and more personnel--such as specialists, paramedicals and researchers--are said to be needed. However, resistance from traditional funding sources--consumers, philanthropists and government--is growing. Rising hospital costs convince us that neither the planners nor hospital governing bodies have found an effective means of supplying quality care at least cost.

Research to identify specific areas for potential cost savings has generally focused on the internal organization of hospitals: the relationship between outputs and inputs and between revenues and costs. K1arman(13) and Anderson and May (1) cite expensive advances in medical technology, catch-up increases in labor expenditures, and the inability of personalservice institutions to take advantage of cost-reducing gains in productivity as major reasons for higher hospital costs.

The external organization of hospitals--their location and capacity to satisfy a population's demands--has been emphasized in research aimed at measuring overall efficiency in the distribution and utilization of hospital services. Milton Roemer $(17,18)$ who examined the relationship between the number of hospital beds in an area and the resulting effect on the use and cost of hospital care, demonstrated the adverse economic effects of excess beds. He showed that often, regardless of medical need, demand for hospital beds expands to meet the available supply; i.e., another application of Parkinson's Law.

Long (15) and other researchers have examined cooperation and regionalization of hospitals as a means of reducing costs. Landgraf (14) demonstrated the economic wastes of excessive duplication of facilities within a geographical area. He pointed to obsolete "inter-hospital competition" for "autonomous isolation" and recommended area-wide planning for a geographical-regional approach. Recently, a study of Boston hospitals $(4,5,6)$ showed how inefficient planning caused an oversupply of beds. These studies have demonstrated the veracity of a widely held belief: that there has been a considerable waste of resources in this country in construction and maintenance of unnecessary hospital beds (16).

As envisioned by Long, cooperation of hospitals in a defined geographical area could involve one large central hospital with smaller, ancillary hospitals or a group of several small or large hospitals. Not every hospital would need to have the minimum number of personnel, range of ski11s 
for example, not every hospital would be required to maintain a large number of beds in excess of the expected daily patient in-flow. Labor, capital and costs of maintaining unused beds thus would be reduced.

In the following analysis, we examine the extent to which federal hospital planning encourages a system of cooperation and regionalism and the cost savings implied in such a system. The necessary conditions for the analysis are simple: the existence or planned existence of one or more hospital service areas. Because federal guidelines related to provisions of Hill-Burton planning and construction funds require that all states have plans outlining such areas, the geographic framework is generally available. This study examines Connecticut, which for hospital planning purposes is divided into 10 health service areas.

\section{METHODOLOGY}

The measure used by most federal hospital planners to determine whether a hospital's size adequately provides for expected needs is the hospital's occupancy rate (OR), which is the number of beds used as a percentage of beds available. It may vary according to changing demand conditions, yet it is usually fairly predictable. A 100-percent OR would imply that all the hospital's beds were used daily over a given period, usually a year; a 50-percent rate would imply that only half the beds were used. An 80-percent $O R$ is considered a comfortable average, with a 20-percent allowance for efficient management in bed turnover.

Long (15), Edwards and Doherty (9), Shonick (19) and others have examined alternatives that focus not on the number of beds needed to satisfy an expected occupancy rate--a method which, in the face of economic losses associated with empty beds, could encourage overutilization--but on the number of beds needed to ensure that demand could be satisfied in an emergency. The approaches, which focus on hospital cooperation and regionalization, are based on a postulation that the number of hospital beds needed increases only in proportion to some fraction of the population to be served. In other words, if a region's population should double, hospital beds should not be doubled; likewise, if two hospitals in two towns plan together, the number of hospital beds needed to serve both towns together will be less than the number needed to serve each independently.

Patient arrivals in general hospitals are assumed to be distributed by a Poisson distribution. Hence, the probability of having $\mathrm{n}$ patients on given day is:

$$
P_{n}=\frac{m^{n} e^{-m}}{n !}
$$

where $\mathrm{m}$ is the mean or expected number or average daily census of patients ${ }^{1}$. A Poisson assumption is appropriate when arrivals are distributed independently over time and when one is concerned with the total number of arrivals during a time interval--that is, when we assume that the probability of an arrival on one day is the same as the probability on any other day and is independent of the number of arrivals on a previous day.

The daily variation in a hospital census can be approximated by the Poisson distribution was initially implied by the Commission on the Cost of Hospital Care in 1947 (11). Since then, the formula has been used as the base of several hospital studies, including those of Long, Edwards and Doherty, and Shonick mentioned previously. Evidence of its justification as a description of the variation in a hospital's census has been only partially completed. Blumberg (3) showed its applicability when the caseload is largely of an emergency nature. Cowan and Roth (8) utilized the formula in examining expected maternity caseloads. More recently, Shonick (19) used it to develop a distribution of patient arrivals in California hospitals. The key point here, however, is the recognition that hospitals can function completely on a daily basis. That is, we assume that in the interests of economy, the infamous weekend lag can be disposed of.

An illustration of this approach to hospital planning may be useful before we proceed with the analysis. If an average daily census of 400 patients $(m=400 ; s=20)$ is anticipated for a new hospital, and the hospital 
is built with exactly 400 beds, the number of patient arrivals would fall within plus or minus one standard deviation of the mean two-thirds of the time--that is, two-thirds of the time the number of patients would range between 380 and 420 . Thus, given the assumptions, we could expect the number of arrivals to exceed 400 with a probability of 33 percent. Such a rate allows little leeway against overcrowding and, in fact, indicates overcrowding possibly once every third day. Because some risk of overcrowding is always present, we might want to have enough beds to reduce the risk on an acceptable level. To ensure that the number of arrivals would not exceed the number of beds on a given day with a probability of one in 1,000 , say, we would want to provide 460 beds, a capacity about three standard deviations above the mean.2

In the following analysis, Connecticut's 1974 hospital bed needs as projected by a federal formula are compared with those projected by the Poisson formula. The federal estimates, which use an optimum occupancy rate criterion, are included in the 1971 Connecticut Construction Plan for Hospital and Medical Facilities (7). These estimates are based on an 80-percent OR, a rate which has been determined largely on an experiential basis as permitting sufficient leeway for effective management. This managerial efficiency criterion has not, however, been empirically validated. In fact, Feldstein (10) has shown the short run managerial cost curve of a hospital be relatively horizontal over the usual range of output, and other studies $(2,22)$ have indicated that an 85 -percent OR provides effective functioning.

In the first set of comparisons, the projections assume that Connecticut's general hospitals operate independently--except for hospitals in cities containing more than one hospital. In these cities, the state construction plan records the total estimated number of needed beds, rather than the number needed for each hospital.

In the second set of comparisons, the number of beds projected in the state plan are again used. This time, the analysis is based not on individual hospital needs, but on beds needed to serve the population of the state's health service areas. Our interest is to determine the extent to which the federal method for determining bed needs in these areas represent a realistic appraisal of the economies of regionalization.

Included in the analysis are Connecticut's nonprofit, short-term general hospitals. ${ }^{3}$ Because the state construction plan recognizes the existence of excess capacity in the pediatric and maternity departments of these hospitals, we concentrate on the medical and surgical beds--a more useful indicator of community needs.

\section{ALTERNATIVE PROJECTIONS OF BED NEEDS}

\section{Independent Hospita1s}

The Poisson formula used below treats hospital planning from the perspective of expected patient population demands. It can, therefore, be applied to a single hospital or to a group of hospitals serving a specific area, such as an economic region or a trading area.

Table 1 shows the number of beds in Connecticut's hospitals in 1969, the number needed by 1974 according to federal estimates, the number needed by our estimates and the difference between the two measures of need.

According to the state construction plan, the expected average daily census of medical-surgical patients in hospital \#06 is 224 in 1974. Federal plans, however, call for 286 beds; this number is 4.14 standard deviations above the expected average daily census. In Table 2 we show that if patient arrivals are Poisson distributed, the probability that overflow will occur in hospital \#06 on any given day is less than .0001. Assuming that a probability level of .001 provides an adequate margin, that hospital has a very low risk of overcrowding and, technically, could operate independently. Hospital \#07 in the same health service area expects 48 patients on a daily basis in 1974. Federal estimates project that 62 beds will be needed. According to Table 2, the probability of overflow with this number of beds is .0228, or once every 44 days. To allow a safety margin sufficient to maintain a .001 level of probable overflow, the hospital should have 69 beds--assuming, that is, that it operates independently of other hospitals. 
Table 1. MEDICAL AND SURGICAL BEDS IN CONNECTICUT'S GENERAL HOSPITALS IN 1969 AND ALTERNATIVE PROJECTIONS FOR 1974

\begin{tabular}{|c|c|c|c|c|}
\hline Hospital & $\begin{array}{c}\text { Actual } \\
1969 \\
\end{array}$ & $\begin{array}{l}\text { Federal } \\
\text { Estimates } \\
\text { For } 1974 \\
\end{array}$ & $\begin{array}{l}\text { Poisson } \\
\text { Estimates } \\
\text { For } 1974 \\
\end{array}$ & $\begin{array}{r}\operatorname{Col} 1.3 \\
\text { vs. Col. } 4 \\
\end{array}$ \\
\hline 01 & 139 & 139 & 149 & -10 \\
\hline 02 & 127 & 147 & 138 & 9 \\
\hline 03 & 71 & 84 & 90 & -6 \\
\hline 04 & 143 & 146 & 148 & -2 \\
\hline 05 & 57 & 57 & 64 & -7 \\
\hline 06 & 190 & 286 & 269 & 17 \\
\hline 07 & 75 & 62 & 69 & 7 \\
\hline 08 & 270 & 293 & 280 & 13 \\
\hline 09 & 190 & 211 & 207 & 4 \\
\hline 10 & 323 & 267 & 249 & 18 \\
\hline 11 & 188 & 217 & 216 & 1 \\
\hline 12 & 230 & 261 & 258 & 3 \\
\hline 13 & 117 & 104 & 111 & -7 \\
\hline 14,15 & 1,181 & 1,215 & 1,113 & 102 \\
\hline $16-18^{a}$ & 1,004 & 1,006 & 896 & 110 \\
\hline 19,20 & 684 & 746 & 674 & 72 \\
\hline 21 & 355 & 340 & 324 & 16 \\
\hline 22 & 316 & 360 & 341 & 19 \\
\hline $23,24^{a}$ & 405 & 556 & 509 & 47 \\
\hline 25 & 0 & 156 & 157 & -1 \\
\hline 26 & 196 & 190 & 198 & -8 \\
\hline $27-30^{\mathrm{a}}$ & 1,792 & 1,859 & 1,706 & 153 \\
\hline 31 & 271 & 364 & 364 & 0 \\
\hline 32 & 410 & 353 & 363 & -10 \\
\hline 33 & 91 & 48 & 60 & -12 \\
\hline 34 & 57 & 53 & 66 & -13 \\
\hline 35 & 94 & 58 & 71 & -13 \\
\hline Total & 8,976 & 9,578 & 9,090 & 488 \\
\hline
\end{tabular}

${ }^{a}$ Combined data from more than one hospital in the same town. 
Table 2. PROBABILITY ${ }^{\mathrm{a}}$ OF DEMAND EXCEEDING BED AVAILABILITY IN CONNECTICUT'S GENERAL HOSPITALS, IF 1974 NUMBER OF BEDS EQUALS FEDERALLY PROGRAMMED NUMBER

\begin{tabular}{cccc}
\hline Hospita1 & Probability & Hospital & Probability \\
\cline { 2 - 3 } 01 & $.0202^{\mathrm{b}}$ & $16-18$ & .0000 \\
02 & $.0019^{\mathrm{b}}$ & $19-20$ & .0000 \\
03 & $.0139_{\mathrm{b}}^{\mathrm{b}}$ & 21 & .0001 \\
04 & $.0030^{\mathrm{b}}$ & 22 & .0001 \\
05 & $.0256^{\mathrm{b}}$ & 23,24 & .0000 \\
06 & $.0000^{\mathrm{b}}$ & 25 & .0001 \\
07 & $.0228^{\mathrm{b}}$ & 26 & .0010 \\
08 & $.0001_{\mathrm{b}}$ & $27-30$ & $.0001 \mathrm{~b}$ \\
09 & $.0011^{\mathrm{b}}$ & 31 & $.0013^{\mathrm{b}}$ \\
10 & $.0001_{\mathrm{b}}^{\mathrm{b}}$ & 32 & $.0013^{\mathrm{b}}$ \\
11 & $.0011^{\mathrm{b}}$ & 33 & $.0013^{\mathrm{b}}$ \\
12 & $.0007 \mathrm{~b}$ & 34 & $.1357^{\mathrm{b}}$ \\
13 & $.0158^{\mathrm{b}}$ & 35 & \\
14,15 & .0000 & & \\
& & & \\
\hline
\end{tabular}

a

Probability is calculated from the normal distribution for $m+z s$ where:

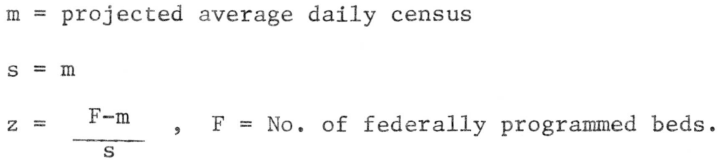

b Hospitals in which the risk of overcrowding is significant ( .0010$)$. 
If we look at the statistical data in Table 1 and 2 , we might conclude that according to the federal estimates, hospital \#06 could function independently because there is little probability of patient sverload. Application of the Poisson formula, however, shows that the hospital would have an excess of 15 beds. On the other hand, in hospital \#07, where patient overflow is likely to occur frequently, we might conclude that this hospital could not function independently. According to the Poisson formula, seven more beds than the federal estimate of 62 would be needed. If these two hospitals were to cooperate, however, the need for more beds in the latter might be taken care of by the excess beds in the former.

In general, the federal estimates and the Poisson estimates compare favorably for the larger hospitals, all of which are located in urban centers. That is, these hospitals can probably function with the number of beds federally programmed without a serious risk of overcrowding. For the smaller, more rural hospitals, however, the Poisson estimates call for more beds than do the federal estimates.

In terms of total 1974 bed needs, the federal estimates project 488 more beds than do the Poisson formula estimates. The excess, however, is almost entirely composed of numbers from the five areas where hospitals have been grouped together. In fact, for hospitals 14-20, 23-24, and 27-30 the number of excess beds is 484 . (Table 1's 1isting of hospitals is the same as that used in the state plan.) Hence, in this part of the analysis --where theoretically all the hospitals operate independently--there is no significant difference between the two estimates of total 1974 hospital bed needs.

But this leads us to the supposition that if several hospitals were to cooperate, savings in bed needs could be realized. For example, the federal estimates indicate that a total of 591 beds $(353+48+190)$ are needed in 1974 for one large hospital (\#32) and two small hospitals (\#33 and \#26), which are all located in proximity to one another. Our estimates that assume these hospitals operate independently show a need for 621 beds (363+ $60+198)$ in 1974. However, if the hospitals cooperate and we consider bed needs in terms of the region's population, we find that with an average daily census of 502 patients, 569 beds would suffice--22 fewer beds than projected by the federal estimates. The probability of overcrowding would be .001 , but this may be too high a risk to consider on a regional basis. To reduce the risk to .0001--that is, overcrowding possibly occurring once in 27 years instead of once in 3 years--the number of beds should be 589 , or approximately the number federally programmed on an individual hospital basis.

This finding suggests that federal planners may be moving from a concept of independence to one of cooperation. But it also focuses attention on the argument that generally the federal method may take insufficient account of the possible economies of regionalization and cooperation and lead to an excessive number of beds. To explore this hypothesis further, we can test federal plans against our alternative, this time assuming that the hospitals are fully regionalized.

\section{Regional Cooperation of Hospitals}

Regional cooperation of hospitals could, as mentioned earlier, reduce hospital costs because personnel, equipment, and bed needs would be less-the hospitals would cooperatively own expensive equipment and jointly use specialized services. Advantages of such a system, offsetting some of the cost economies that a single large hospital may still enjoy, despite equipment sharing, would be in patients' nearness to home and doctors' nearness to patients. Transfers involving long travel would occur only in complicated cases necessitating specialized equipment available in another hospital. There is, however, no reason to suggest that more travel would be involved if this were the case than if there were only one central hospital.

In the following discussion, we assume that the 10 health service areas into which Connecticut is divided form the geographical base for such regions. To do this, of course, is no venture. The reason for dividing states into service areas is, presumably, to take advantage of regional cooperation and its implications for economizing on hospital facilities and nanpower. 
Table 3 shows estimates of 1974 hospital bed needs in the 10 areas according to the federal formula and our Poisson formula. Area totals in the federal column are the sum of individual hospital projections given in the state plan and shown in Table 1. Totals in the Poisson formula columns were calculated by applying the formula with (1) 3.00 standard deviations to obtain $\mathrm{p}=.001--$ that is, a risk of overcrowding once in 1,000 days method (1) and (2) with 3.88 standard deviations to obtain $\mathrm{p}=.0001$, a risk of overcrowding once in 1,000 days (method 11), to the average daily census of hospital patients projected for each service area.

In the previous sections, our estimates were based on the number of beds needed to satisfy a risk level selected on the premise than an independent hospital within its area. Now, however, we are dealing with the probability of overcrowding on a regional basis. In this case, a p-.001 may be unrealistically low because transference across regions would involve uneconomical logistical complexities. A lower risk, e.g., p-.0001, should provide regional planners with sufficient latitude within which to work.

Compared with the federal estimates, our method 1 estimates ( $\mathrm{p}-.001$ ) would reduce the number of additional beds by 993, while our method 11 estimates $(p=.0001)$ would reduce it by 765 . Both methods, therefore, yield significant reductions. Because of its posed greater realism, we shall concentrate on method 11 for the remainder of the analysis.

The biggest absolute reductions in bed needs estimated by method 11 occur in areas where the expected average daily census is highest, the state's heavily urbanized areas. This result is to be expected from the mathematical composition of the formula used. But it supports the suggestion that application of the 80-percent optimum occupancy rate by federal planners as a basis for estimation is rigid.

Table 4 and Figure 1 show that as the expected average daily census increases from 200 to 2,600 patients, the federal OR increases from 78.3 to 81.0 , whereas the OR based on method 11 increases from 78.9 to 93.0 . What these results mean is that federal planners adhere to a relatively rigid occupancy rate and, when we assume that patient arrivals are Poisson distributed, allow risks of overcrowding to vary on any given day--in this case from one in 10,000 in area $\mathrm{E}$, a rural area, to one in 100,000 in area $\mathrm{J}$, an urban area. In contrast to the federal approach, the one we use focuses on risks of overcrowding and allows ojcupancy rates to vary.

The effects of the two approaches are indicated by their results in terms of bed needs. That a potential reduction of 765 beds, 8 percent, from the number federally programmed, is not financially insignificant will be shown. First, however, we want to emphasize that the operational difference between the two methods emerges after an expected daily census of 200 patients. Thus, the standard OR approach may be an acceptable criterion for judging bed needs in relatively rural areas served by a single hospital or a group of small hospitals willing to cooperate. It does not, however, extend these advantages to more densely populated areas.

To emphasize how method 11 of the Poisson formula does capture these advantages, Table 5 compares the number of beds that should be added to the 1969 number according to that method and according to the federal projections.

The federal estimates indicate a need for 602 additional beds in 1974 . Our method indicates that the 1974 number of beds, rather than being more than the 1969 number, could be 103 less. The absolute sum of these bed numbers is 765. The number corresponds with an earlier finding (Table 3) where a difference of 765 beds between federal and Poisson estimates was shown. Table 5 is therefore simply another way of examining the same data. The approach used, however, emphasizes the potential difference between a regional program based on full hospital cooperation and risk-sharing and one based on limited cooperation and rigid occupancy rates. It suggests that the federal approach is constrained from eliminating possibilities for constructing significantly more hospital beds than an area's population can be expected to use.

There is, however, a final point to make before considering the cost implications of these differences. The figures in Table 5 are two measures of optimum bed requirements. That the number of beds should be reduced below the 1969 level in area $\mathrm{E}$ in the federal estimates and in areas E, F, G 
Table 3. ESTIMATES OF 1974 HOSPITAL BED NEEDS IN CONNECTICUT'S HEALTH SERVICE AREAS ACCORDING TO ALTERNATIVE PLANNING CRITERIA

\begin{tabular}{|c|c|c|c|c|c|c|}
\hline \multirow[b]{2}{*}{ Area } & \multirow{2}{*}{$\begin{array}{c}\text { Projected } \\
\text { Average } \\
\text { Daily } \\
\text { Census } \\
\end{array}$} & \multicolumn{3}{|c|}{ Bed Numbers Estimated By-- } & \multicolumn{2}{|c|}{$\begin{array}{c}\text { Differences Between } \\
\text { Federal and Poisson } \\
\text { Estimates }\end{array}$} \\
\hline & & $\begin{array}{c}\text { Federal } \\
\text { Estimates } \\
\end{array}$ & $\begin{array}{l}\text { Poisson } \\
\text { Method } 1 \\
(\mathrm{p}=.001) \\
\end{array}$ & $\begin{array}{l}\text { Poisson } \\
\text { Method } 11 \\
(\mathrm{p}=.0001)\end{array}$ & $\begin{array}{l}\text { Col. } 4- \\
\text { Col. } 3 \\
\end{array}$ & $\begin{array}{l}\text { Col. } 5- \\
\text { Col. } 3 \\
\end{array}$ \\
\hline $\mathrm{A}$ & 224 & 286 & 269 & 284 & 17 & 2 \\
\hline$B$ & 226 & 287 & 271 & 284 & 16 & 3 \\
\hline $\mathrm{C}$ & 272 & 348 & 320 & 356 & 28 & 12 \\
\hline $\mathrm{D}$ & 402 & 504 & 462 & 480 & 42 & 24 \\
\hline$E$ & 207 & 267 & 249 & 263 & 18 & 4 \\
\hline $\mathrm{F}$ & 1,455 & 1,797 & 1,569 & 1,603 & 228 & 194 \\
\hline G & 811 & 1,006 & 896 & 921 & 110 & 85 \\
\hline $\mathrm{H}$ & 600 & 746 & 674 & 695 & 72 & 51 \\
\hline I & 1,009 & 1,256 & 1,105 & 1,132 & 151 & 124 \\
\hline$J$ & 2,617 & 3,081 & 2,770 & 2,815 & 311 & 266 \\
\hline Total & 8,976 & 9,578 & 8,585 & 8,813 & 993 & 765 \\
\hline
\end{tabular}


Table 4. OPTIMUM 1974 OCCUPANCY RATES FOR HOSPITALS IN CONNECTICUT'S HEALTH SERVICE AREAS ACCORDING TO ALTERNATIVE PLANNING CRITERIA

\begin{tabular}{|c|c|c|c|}
\hline \multirow[b]{2}{*}{ Area } & \multirow[b]{2}{*}{$\begin{array}{c}\text { Projected Average } \\
\text { Daily Census } \\
\end{array}$} & \multicolumn{2}{|c|}{ Occupancy Rates According to--- } \\
\hline & & Federal Estimates & $\begin{array}{c}\text { Poisson } \\
\text { Method } 11 \text { Estimates }\end{array}$ \\
\hline A & 224 & 78.3 & 78.9 \\
\hline $\mathrm{B}$ & 226 & 78.7 & 79.6 \\
\hline $\mathrm{C}$ & 272 & 78.2 & 80.1 \\
\hline D & 402 & 79.8 & 83.8 \\
\hline $\mathrm{E}$ & 207 & 77.5 & 78.7 \\
\hline $\mathrm{F}$ & 1,455 & 80.5 & 90.7 \\
\hline G & 811 & 80.6 & 88.1 \\
\hline $\mathrm{H}$ & 600 & 80.4 & 86.3 \\
\hline I & 1,009 & 80.3 & 89.1 \\
\hline \multirow[t]{2}{*}{$\begin{array}{l}\mathrm{J} \\
\mathrm{J}\end{array}$} & 2,617 & 81.0 & 93.0 \\
\hline & & Range $77.5-81.0$ & Range $78.7-93.0$ \\
\hline
\end{tabular}




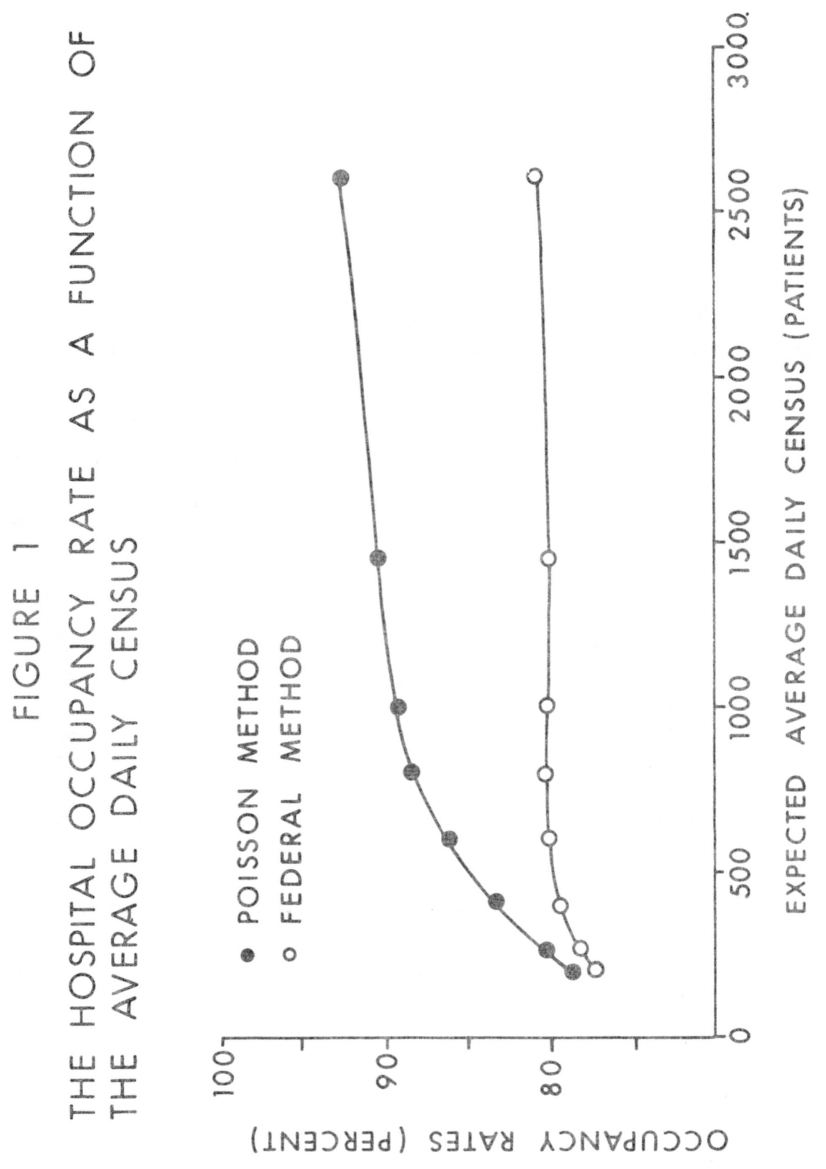


and $\mathrm{H}$ in our estimates cannot, however, be used to reduce the number of beds to be constructed in other areas. That is, we cannot balance excess beds in one area against deficient beds in another. To use this approach, simply add the positive number in Table 5. The result, shown as new bed needs at the base of the table, is that according to the federal program, 658 beds should be built and according to our proposal, 189 beds should be built.

Table 5. ADDITIONAL HOSPITAL BEDS NEEDED IN CONNECTICUT'S HEALTH SERVICE AREAS IN 1974 ACCORDING TO ALTERNATIVE PLANNING CRITERIA

Additional Bed Needs According to--

\begin{tabular}{crrr} 
& & & \multicolumn{2}{c}{$\begin{array}{c}\text { Poiss } \\
\text { Area }\end{array}$} & 1969 Beds & Federal Estimates & Method 11 \\
\cline { 2 - 2 } A & 266 & 20 & 18 \\
B & 271 & 16 & 13 \\
C & 265 & 83 & 71 \\
D & 460 & 44 & 20 \\
E & 323 & -56 & -60 \\
F & 1,716 & 81 & -113 \\
G & 1,004 & 62 & -83 \\
H & 684 & 180 & 11 \\
I & 1,076 & 170 & -96 \\
J & 2,911 & 602 & -163 \\
& Total & 658 & 189
\end{tabular}

\section{COST IMPLICATIONS}

To this point, this analysis has shown the potential saving in hospital beds that application of our formula allows. Our final step is to transform these bed savings into dollars.

An estimate of the construction cost per hospital bed in Connecticut is $\$ 63,000.4$ Should plans in Connecticut develop along the lines advocated in the federal program, 658 additional hospital beds will have teen constructed by 1975 at a cost of $\$ 41,454,000$. On the other hand, should our alternative be adopted, 189 additional beds will have been constructed for a cost of $\$ 11,907,000$. The difference is 469 beds or $\$ 29,547,000$. This figure is presented as a measure of potential excess expenditures on hospital construction in Connecticut for a period 1969-74.

To determine the effect of this expenditure on patients, we can transform it inot daily hospital service charges. The daily cost of an unused hospital bed, made up of fixed plus maintenance costs, has been put at three-fourths the daily cost of a used bed (20). Hospital costs per day in Connecticut in 1971 were $\$ 102$ (12); assuming an increase of 10 percent per year, 5 costs will be $\$ 135$ per day in 1974 .

Using $\$ 102$ (assuming effective price stabilization) and $\$ 135$ as lower and upper bounds, we estimate unused bed costs at between $\$ 76.50$ and $\$ 101.25$ per day. On an annual basis, the figures amount to $\$ 27,923$ and $\$ 36,956$ per bed, or $\$ 13,095,887$ and $\$ 17,332,364$ for 469 beds. With an expected average daily census of 7,823 patients in Connecticut's hospitals in 1974, the average daily additional per patient charge attributable to the cost of unused beds will be between $\$ 4.50$ and $\$ 6.07$. 


\section{CONCLUSIONS}

Hospital bed needs in 1974 as determined by a federal formula--based on optimum occupancy rates--and by an alternative approach--based on assumed patient arrivals--showed that when hospitals were considered to operate independently, the two approaches yielded approximately similar results. When the hospitals were considered in area groupings, however, the federal plan called fro 765 more beds than did the alternative plan. The 1974 cost of these extra beds was estimated to be between $\$ 7$ and $\$ 10$ per hospitalized patient per day. When account was taken of additions to the stock of 1969 beds, it was found that whereas the federal plan indicated a need for 658 more beds, the alternative indicated a need for an additional 189 beds. It was estimated that the difference of 469 beds would cost $\$ 29.5$ million in construction expenditures and account for between $\$ 4$ and $\$ 7$ of the average daily hospital charge.

The differences permit us to conclude that: (1) Regionalization plans for hospitals may not yet have been developed to the point where significant cost savings in construction and maintenance costs can be realized; and (2) standard approaches to hospital planning, through understating the potential for hospital cooperation and overstating the risks of overcrowding, may help maintain the status quo exemplified by undercooperation and uneconomic duplication rather than encourage greater efficiency.

The method used in this study is not new and is not intended as a panacea for the problems facing hospital planners. But, besides its simplicity and objectivity, its advantages are: (1) it focuses attention on regionalization and cooperation among hospitals and (2) it shifts the emphasis in planning hospital size from one that relies on a fixed excess capacity specification regardless of the size of the hospital to one that considers regional demographic characteristics and probable entry patterns.

The principal involved is an aspect of economies of scale: efficiencies of agglomeration. This is, that a single source of service for all consumers in an area has economies not available if the market is divided. In light of the findings of this study and taken from the perspective of using hospital regionalization to promote economical resource allocation, it is pertinent to question the validity of the methods adopted by federal planners. But above this, the question that should be asked is: Is the provision of bed capacity in hospitals an efficient use of scarce resources generally and in the health field particularly? Are there not, in fact, other porgrams presently underfunded to which such resources might more economically be allocated? 


\section{FOOTNOTES}

*Assistant Professor and Research Assistant, respectively, Department of Behavioral Science and Community Health, University of Connecticut Health Center, Hartford, Connecticut.

$1_{\text {When }} \mathrm{m}$ is large, the Poisson distribution is approximated by a normal distribution. Also in the Poisson distribution, the standard deviation(a) is equal to the square root of the mean.

${ }^{2}$ Calculated from the cumulative normal distribution, where the area to the right of the mean plus three standard deviations equals $0.500-0.499$ or 0.001 .

${ }^{3}$ Individual hospitals and locations are not explicitly identified in this study solely because to do so could detract from a major objective, which is to examine the economic implication of alternative methods of hospital planning.

${ }^{4}$ The figure was derived from an average of costs for general hospitals in New York and Massachusetts as estimated by Hil1-Burton (21). Comparable data for Connecticut were unavailable. The estimate is probably quite conservative.

5 The average annual increase during 1967-71 was 16.1 percent. During $1970-71$, the rate was 11.7 percent (23).

\section{REFERENCES}

1. Anderson, Ronald, and Joel May, "Factors Associated with the Increasing Cost of Hospital Care," The Annals CCCXCIX (January, 1972), 62-72.

2. Bailey, Norman, "Calculating the Scale of In-patient Accomodation" in Towards A Measure of Medical Care. London: Oxford University Press, 1962, pp. 55-65.

3. Blumberg, Mark, "Distinctive Patient Facilities Concepts Helps Predict Future Hospital Bed Needs," Modern Hospital, XCVII (December, 1961), 75.

4. The Boston Globe, "Hospital Expansion Unregulated," October 11, 1971.

5. The Boston Globe, "Unneeded Hospital Beds Drain on Paying Public," October 12, 1971.

6. The Boston Sunday Globe, "Unneeded Hospital Beds as Cause of Soaring Patient Costs," October 10, 1971.

7. Connecticut Construction Plan for Hospital and Medical Facilities, 1971. Hartford: Connecticut State Department of Health, 1971.

8. Cowan, Peter, and Kenyon Roth, "Determining the Maternity Case Load by Means of a Poisson Process," British Journal of Preventative and Social Medicine, XVIII (April, 1964), 105.

9. Edwards, Clark, and Neville Doherty, "Hospital Sizes for Rural Areas When Patient Arrivals are Poisson Distributed," Agricultural Economics Research, XXII (October, 1971), 101-104.

10. Feldstein, Paul, An Empirical Investigation of the Marginal Cost of Hospital Services, Chicago: University of Chicago, 1961. 
11. Hospital Care in the United States. New York: Commission of Hospital Care, 1947.

12. Hospitals, Journal of the American Hospital Association, XLV (August, 1971), 2-468.

13. Klarman, Herbert, "Increased Cost of Hospital Care" in The Economics of Health and Medical Care. Ann Arbor: University of Michigan Press 1964, p. 227.

14. Landgraf, Walter, "Needed: New Perspective on Health Services," Harvard Business Review, XLV (September, 1967), 75.

15. Long, Millard, "Efficient Use of Hospitals" in The Economics of Health and Medical Care. Ann Arbor: University of Michigan Press, 1964, p. 2 .

16. Los Angeles Times, Editoria1, March 29, 1972.

17. Roemer, Milton I., "Bed Supply and Hospital Utilization: A Natural Experiment," Hospitals, Journal of the American Hospital Association, XXXVI (November, 1961), 36.

18. Roemer, Milton I., and Max Schoen, Hospital Utilization Under Insurance. Chicago: American Hospital Association, Monograph No. 6, 1959.

19. Shonick, William, "Understanding the Nature of the Random Fluctuations of the Hospital Daily Census: An Important Planning Too1," Medical Care, X (March-April, 1972), 118-139.

20. Somers, Herman, and Anne Somers, Doctors, Patients and Health Insurance. Washington: The Brookings Institute, 1961, pp. 197-198.

21. U.S. Department of Health, Education and Welfare, Representative Construction Costs of Hospitals and Related Facilities (Hill-Burton). Washington; U.S. Governmetn Printing Office, January-October, 1970.

22. U.S. Department of Health, Education and Welfare, U. S. Public Health Service, Areawide Planning for Hospitals and Related Facilities. Washionton: U.S. Government Printing Office, 1961.

23. U.S. Department of Labor, Bureau of Labor Statistics, The Consumer Price Index for December 1971. Washington: U.S. Government Printing Office, December 1971. 